\title{
Parametric Study on Dynamic Response of Fiber Reinforced Polymer Composite Bridges
}

\author{
Woraphot Prachasaree, ${ }^{1}$ Attapon Sangkaew, ${ }^{1}$ \\ Suchart Limkatanyu, ${ }^{1}$ and Hota V. S. GangaRao ${ }^{2}$ \\ ${ }^{1}$ Department of Civil Engineering, Prince of Songkla University, Hat Yai, Songkhla 90112, Thailand \\ ${ }^{2}$ Constructed Facilities Center, Benjamin M. Statler College of Engineering and Mineral Resources, West Virginia University, \\ Morgantown, WV 26505, USA \\ Correspondence should be addressed to Woraphot Prachasaree; pworaphot@eng.psu.ac.th
}

Received 16 May 2015; Accepted 24 August 2015

Academic Editor: Jian-Guo Dai

Copyright (C) 2015 Woraphot Prachasaree et al. This is an open access article distributed under the Creative Commons Attribution License, which permits unrestricted use, distribution, and reproduction in any medium, provided the original work is properly cited.

\begin{abstract}
Because of high strength and stiffness to low self-weight ratio and ease of field installation, fiber reinforced polymer (FRP) composite materials are gaining popularity as the materials of choice to replace deteriorated concrete bridge decks. FRP bridge deck systems with lower damping compared to conventional bridge decks can lead to higher amplitudes of vibration causing dynamically active bridge deck leading serviceability problems. The FRP bridge models with different bridge configurations and loading patterns were simulated using finite element method. The dynamic response results under varying FRP deck system parameters were discussed and compared with standard specifications of bridge deck designs under dynamic loads. In addition, the dynamic load allowance equation as a function of natural frequency, span length, and vehicle speed was proposed in this study. The proposed dynamic load allowance related to the first flexural frequency was presented herein. The upper and lower bounds' limits were established to provide design guidance in selecting suitable dynamic load allowance for FRP bridge systems.
\end{abstract}

\section{Introduction}

Fiber reinforced polymer (FRP) composites have increasingly been accepted for use in civil and military infrastructure systems. In general, fiber reinforced polymer (FRP) composites are a combination of fiber reinforcement and polymer matrix. Normally, FRP composites also contain fillers and additives to modify and enhance material properties. Compared to conventional construction materials such as steel and concrete, FRP composite materials have high specific ratios of stiffness and strength per unit self-weight in addition to excellent corrosion resistance leading to longer service life. Over the past half-century numerous applications in many diverse fields such as aerospace, aircraft, marine and offshore, mechanical industries, renewable energy harvesting application, sport, medical applications and automotive (e.g., utility poles for electrical and communication utility, rapidly deployable housing, pipeline for sewage and sea-water applications, FRP turbine blades for wind energy, cold water pipe for ocean thermal energy conversion, and chimneys/flues in harsh environmental applications) have been noted [1]. However, many applications in infrastructure have been launched since the 1990s. FRP composite materials with various shapes are being used to strengthen and even retrofit structural members. One of the most attractive applications is to replace old deteriorated conventional concrete bridge deck with lightweight FRP deck system. Currently, modern bridge designs to upgrade or even in new bridge construction, with lighter FRP composite structural members are being used for longer span and heavier vehicles. Thus, dynamic response becomes one of the most important issues concerning the design and installation of FRP bridges. In general, the dynamic response under moving loads can induce higher structural responses on FRP bridge decks than in static response conditions. Previous studies [2-4] on FRP bridges under dynamic loads have been limited. From experimental field testing, the dynamic responses of three FRP bridges in West Virginia, United States of America, were evaluated for 
TABLE 1: Mechanical properties of laminates for ProDeck4 and ProDeck8.

\begin{tabular}{lcccccc}
\hline FRP deck & Laminate & $E_{11}\left(10^{4} \mathrm{MPa}\right)$ & $E_{22}\left(10^{4} \mathrm{MPa}\right)$ & $G_{12}\left(10^{4} \mathrm{MPa}\right)$ & $v_{12}$ & Tensile strength $(\mathrm{MPa})$ \\
\hline \multirow{3}{*}{ ProDeck4 } & CDBM 3415 & 3.84 & 0.94 & 0.47 & 0.27 & 350 \\
& DDBM 4015 & 3.88 & 0.95 & 0.46 & 0.28 & 330 \\
\hline \multirow{3}{*}{ ProDeck8 } & Roving & 4.24 & 1.04 & 0.25 & 0.28 & - \\
& CDBM 3415 & 3.38 & 0.58 & 0.24 & 0.26 & 350 \\
& CDB 400 & 3.59 & 0.61 & 0.29 & 0.26 & 310 \\
\hline
\end{tabular}

natural frequency, damping, and dynamic load allowance. The measured dynamic load allowances were found to be as high as 0.93 when compared with the typical design value of 0.33 [2]. The dynamic study on FRP bridges also showed that the sectional configuration of bridge decks has seriously accentuated the superstructure dynamic responses when compared with conventional bridges [3]. Earlier researchers have established that the dynamic response of FRP bridge system is most sensitive to vehicle speed and types with observed dynamic load allowance of 0.71 [4]. From extensive review, it is also found that most dynamic load allowance equations provided in bridge design standards [5-16] are applicable to conventional bridges, but not for FRP bridge deck stiffened superstructure systems.

The objective of this study is to investigate the dynamic response such as natural frequencies and dynamic load allowances for design purposes. The influences of bridge geometry, vehicle speed, and positions on the dynamic response are also evaluated herein. As mentioned above, there is little progress in the dynamic responses on FRP deckstringer bridge systems. The present study is expected to fill the gap partially and to analyze and design FRP bridge deck stiffened superstructural systems by conducting the abovementioned parametric study. Since the field study of dynamic behavior of FRP bridge deck systems is expensive and time consuming, the parametric study as a function of bridge deck type and vehicle parameters has been carried out using finite element analysis.

\section{Multi-Cellular FRP Bridge Decks}

In this study, two different FRP bridge decks, commercially known as ProDeck4 and ProDeck8, were modeled for their dynamic responses. Their structural performance and design issues were comprehensively evaluated [17-19]. The dynamic response in this study is presented as a sequel to static response of the two FRP bridge decks. Both ProDeck 4 and ProDeck8 are developed to sustain AASHTO (American Association of State Highway and Transportation) HS25 truck load.

These FRP decks are produced by pultrusion method. In general, the predominant fibers in applications of structural members are glass, carbon, and organic fiber with a thermoset resin used for the pultrusion process. However, glass fibers (particularly E glass fibers) combined with polyester or vinyl ester resins become the most common uses for FRP bridge decks. The multicellular shaped low-profile FRP ProDeck4 is made of E-glass fiber and vinyl ester resin. Fiber architectures of ProDeck 4 were designed with three main laminates as (1) warp triaxial fabrics (combined with glass mat) known as CDBM $3415\left(0^{\circ} / 45^{\circ} /-45^{\circ} / \mathrm{CSM}\right)$; (2) weft triaxial fabrics (combined with glass mat) known as DDBM 4015 (multidirectional fabric laminate $\left.\left(45^{\circ} / 90^{\circ} /-45^{\circ} / \mathrm{CSM}\right)\right)$; and (3) continuous strand rovings. CDBM and DDBM laminates are a stitch bonded composite fabric combining double bias $\left(45^{\circ} /-45^{\circ}\right)$ piles with warp $\left(0^{\circ}\right)$ or $\left(90^{\circ}\right)$ into a single multidirectional fabric for CDBM or DDBM, respectively. Also, each laminate fabric is combined with a continuous glass mat for enhancing thermomechanical properties.

Similarly, three different laminates of ProDeck8 are (1) CDBM 3415 (multidirectional fabric laminate with orientation and stacking sequence $\left.\left(0^{\circ} / 45^{\circ} /-45^{\circ} / \mathrm{CSM}\right)\right)$; (2) biaxial fabrics known as CD400 (bidirectional fabric laminate of $\left.45^{\circ} /-45^{\circ}\right)$; and (3) continuous strand roving. ProDeck8 module has a rectangular cross section with a diagonal stiffener. Both ProDeck 4 and ProDeck 8 have fiber volume fraction of approximately 50 percent. The laminated fabrics of both FRP bridge decks continue from the flange to web and then again to the flange. The high elongation polymer used for both FRP decks was vinylester resin. Typically, FRP composite materials exhibit thermomechanical properties of varying magnitudes in different directions. Thus, the component stiffness of FRP deck modules can be determined using the interaction properties of constitutive materials in each composite layer. The mechanical properties of FRP deck modules to model ProDeck 4 and ProDeck 8 deck systems are given in Table 1. In addition, fiber architecture and laminate stacking sequence of both FRP deck modules are presented in Figure 1.

\section{Bridge Configurations}

In this study, two-lane FRP decks and steel stringer bridges were modeled to perform the dynamic responses of the superstructure system. Multicellular FRP decks (ProDeck4 and ProDeck8) and H-shape wide flange steel stringers were assembled together for all bridge superstructure models. The width of the bridge models was chosen to be a constant $9.50 \mathrm{~m}$ in width for two traffic lanes. Two different span lengths (12 and $18 \mathrm{~m}$ ) of single span bridge systems were selected with steel wide flange stringer size of W $36 \times 150$. The various steel stringer spacings were considered to be $1.22,1.83$, and $2.24 \mathrm{~m}$ for modeling with 7, 5, and 4 steel stringers, respectively, with typical arrangement as shown in Figure 2. 


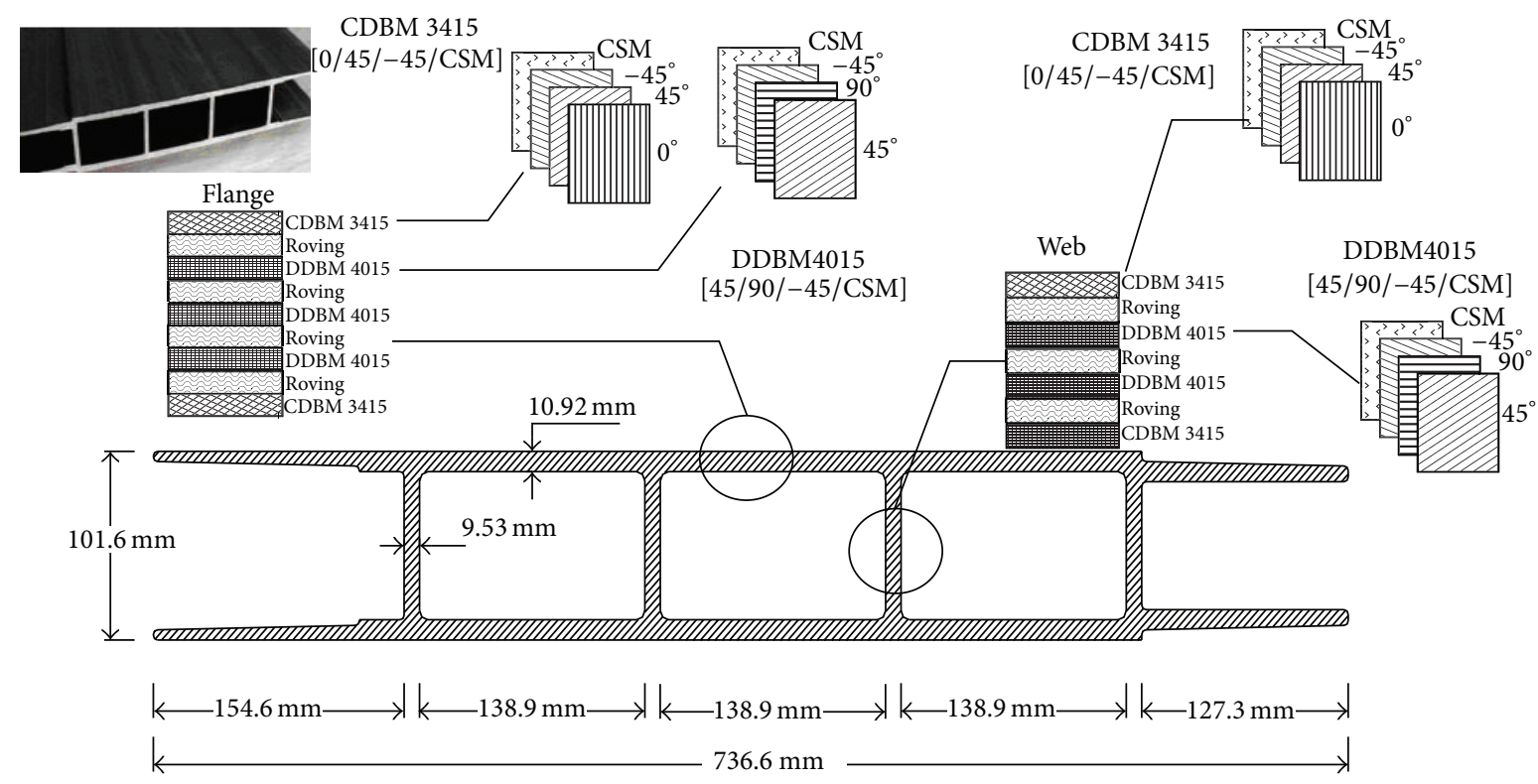

(a) ProDeck4

CDBM 3415

$[0 / 45 /-45 / \mathrm{CSM}]$
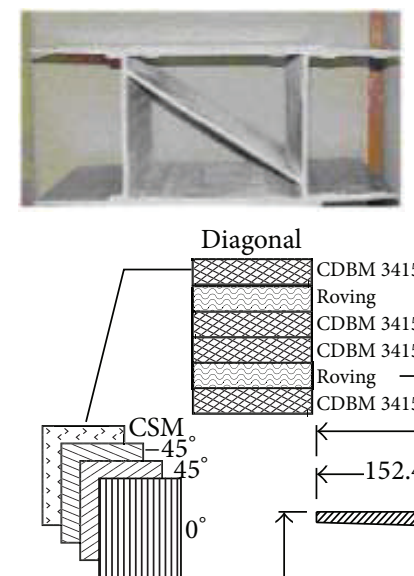

Diagonal

CDBM 3415

$[0 / 45 /-45 / \mathrm{CSM}]$

蓶然 CDBM 3415

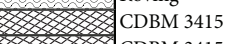

CDBM 3415

Roving
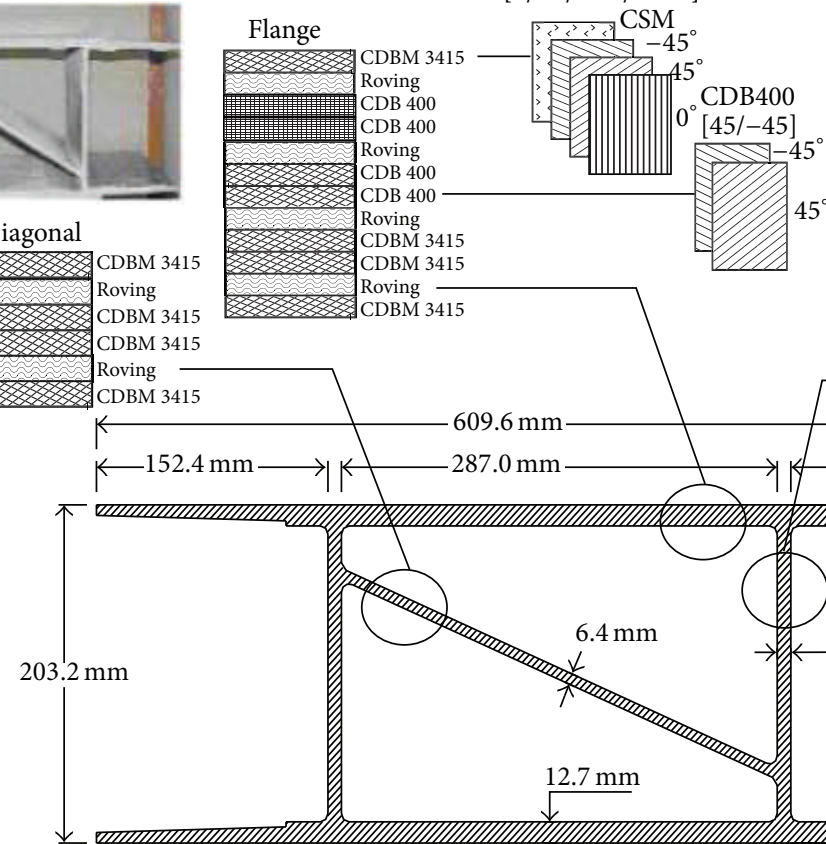

Roving 1415
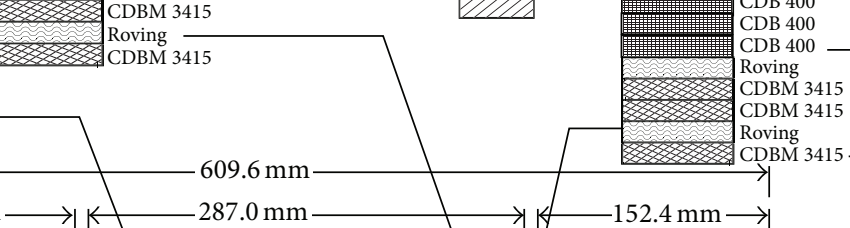

Web

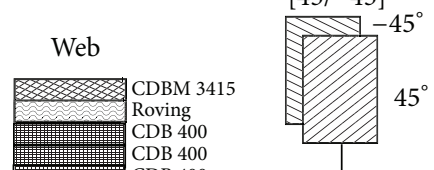
W CDB 400

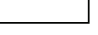

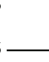

\section{$152.4 \mathrm{~mm} \longrightarrow$}
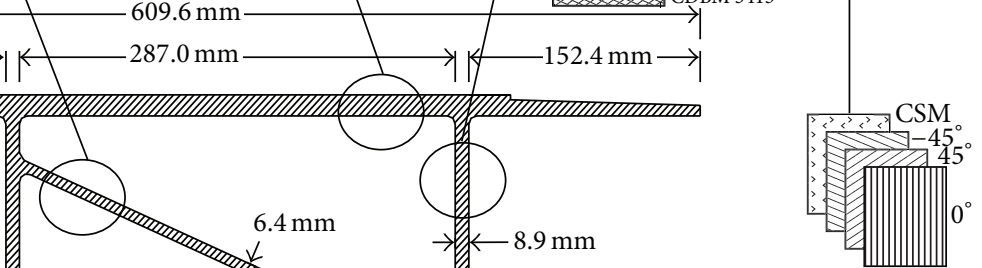

CDBM 3415

$[0 / 45 /-45 / C S M]$

(b) ProDeck8

FIGURE 1: Fiber architecture and stacking sequence.

\section{Loading Patterns}

In general, the dynamic response of bridge superstructure models depends on many factors, including vehicular loading patterns, bridge configurations, road surface conditions, and vehicle speeds. Three different dynamic loading patterns were simulated as follows:

Loading pattern 1 (Case A): a single truck travels along the bridge span.
Loading pattern 2 (Case B): two trucks travel along the span in the same direction.

Loading pattern 3 (Case C): two trucks travel along the span in the opposite direction.

To evaluate maximum dynamic deflection and observe critical vehicle speed, the truck loading speed is varied between $20 \mathrm{~km} / \mathrm{hr}$ and $100 \mathrm{~km} / \mathrm{hr}$ with an interval $20 \mathrm{~km} / \mathrm{hr}$. The AASHTO HS25 trucks were selected to simulate the design truck loading conditions. In addition, there are six different 
TABLE 2: Bridge model parameters.

\begin{tabular}{|c|c|c|c|c|c|c|c|c|c|}
\hline \multirow{2}{*}{ Bridge model } & \multicolumn{9}{|c|}{ Parameters } \\
\hline & Deck type & Bridge length & Traffic direction ${ }^{*}$ & Speed $(\mathrm{km} / \mathrm{hr})$ & Number of stringers & $W_{\text {total }}(\mathrm{m})$ & $W_{\text {traffic }}(\mathrm{m})$ & $S(\mathrm{~m})$ & $d(\mathrm{~m})$ \\
\hline G7 & & & & & $7(W 36 \times 150)$ & & & 1.22 & 0.91 \\
\hline G5 & P4, P8 & $12,18 \mathrm{~m}$ & $\uparrow, \uparrow \uparrow$, and $\uparrow \downarrow$ & $20,40,60,80$, and 100 & $5(W 36 \times 150)$ & 10.10 & 9.14 & 1.83 & 0.91 \\
\hline G4 & & & & & $4(W 36 \times 150)$ & & & 2.24 & 1.21 \\
\hline
\end{tabular}

Note. ${ }^{*}$ Traffic direction: $\uparrow$ a single truck travels along the bridge span, $\uparrow \uparrow$ two trucks travel along the span in the same direction, and $\uparrow \downarrow$ two trucks travel along the span in the opposite direction. P4 = ProDeck4, P8 = ProDeck8.

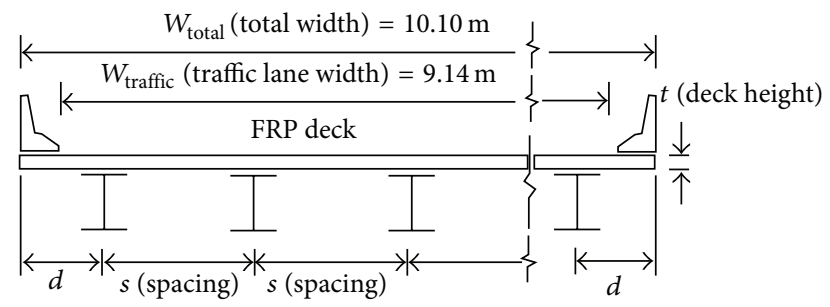

FIgURE 2: Typical bridge model configuration.

bridge geometry models evaluated with three (truck) loading patterns. For loading pattern 1 (1-truck loading), three loading positions are follows: (1) left wheel is placed directly over the centerline of the exterior stringer (A-1); (2) left wheel is placed directly over the centerline of the first interior stringer (A-2); and (3) truck loading is placed on the middle of the traffic width (A-3). The two truck loadings (loading patterns 2 and 3) consisted of the same loading positions as case of one truck loading; that is, (4) left wheel of the left truck is placed directly located on the centerline of the exterior stringer (B1, C-1), (5) left wheel of the left truck is placed directly over the centerline of the first interior stringer (B-2, C-2); and (6) center line between both trucks corresponds to the center line of the traffic width (B-3, C-3). Totally, nine subcases of (truck) loading conditions were investigated for each bridge model. All bridge models and design truck loading conditions are demonstrated and summarized in Table 2 and Figure 3.

\section{Finite Element Modeling}

A general purpose finite element modeling and analysis package, ANSYS [20], with a pre- and postprocessor program was employed herein for dynamic analysis of FRP bridge deck system. Bridge superstructure geometry, nodes, elements, and element meshes were automatically generated by ANSYS. Generally, the truck loading conditions are well below the critical stress leading to nonlinear geometry and material behavior of bridge system models [21]. Thus, the finite element models based on linear elastic analysis are adopted in this parametric study. The load-deflection response of a single ProDeck4 module is presented in the Appendix. ProDeck4 and ProDeck8 are modeled using orthotropic laminated shell elements (SHELL93 [20]). Eight-node SHELL93 element had six degrees of freedom at each node (translations in the nodal $x, y$, and $z$ directions and rotations about the nodal $x$-, $y$ , and $z$-axes). FRP deck models are assembled using two main components as (1) flange and (2) web portions. The material properties of FRP deck models are shown in Table 1. The fiber orientation in each layer of a laminate is followed by the fiber architecture as shown in Figure 1. The web and flange steel stringer are modeled using the quadrilateral isotropic shell elements. A bilinear stress and strain relation of Grade 36 steel with elastic modulus of $200 \mathrm{GPa}$ is used for steel stringers. All parts of the finite element FRP deck and steel stringer models are bonded together. The interaction at the FRP deck and stringer interfaces is modeled as having $100 \%$ structural composite and noncomposite actions in all FRP bridge deck system models. For $100 \%$ compositeness, the interface between FRP deck and steel stringer model is completely connected; thus, $100 \%$ structural composite action at the model interface is attained. In order to develop noncomposite behavior, the interface or link elements are introduced between FRP bridge deck and steel stringers as shown in Figure 4. The high vertical stiffness compared with in-plane transverse stiffness of the interface or link element can be used for this purpose. The boundary conditions were assigned to be roller type (constrained in bridge $x$ and $z$ directions) and pinned (constrained in bridge $x, y$, and $z$ directions) at the end of steel stringers. The finite element models of FRP bridge decks with steel stringers developed following the above principles were made to investigate the dynamic responses under HS-25 truck loading conditions.

Structural damping in superstructure models includes material and structural damping. In general, most of the steel wide flange stringer bridges inherently have little variation in damping, especially if the deck is made of concrete. Thus, damping is not a main parameter to control the responses of a bridge [22]. However, accurate damping is needed for structural evaluation of accurate dynamic responses. It is found that low self-weight and low damping $(0.5 \%$ from field data and previous studies $[2,3,23]$ ) can lead to excessive vibration of an FRP deck-steel stringer bridge. Therefore, the damping ratio of $0.5 \%$ was also employed in this parametric study. For dynamic truck loading simulation, AASHTO HS25 (see Figure 5) that resembles a semitrailer truck was selected for a vehicular load. The front axle is $44 \mathrm{kN}$, positioned $4300 \mathrm{~mm}$ behind the drive axle that is $178 \mathrm{kN}$, and the rear trailer axle is also $178 \mathrm{kN}$ and is located at a distance of $4300 \mathrm{~mm}$. To simulate a moving truck, subroutine programs of the load step method were imposed on the finite element program package. In this method, truck axles on a bridge model will move forward with a constant distance for each steppingtime increment as demonstrated in Figure 6. The number of discrete time instants depends on length of bridge span. To incorporate bridge surface roughness, the power spectral 


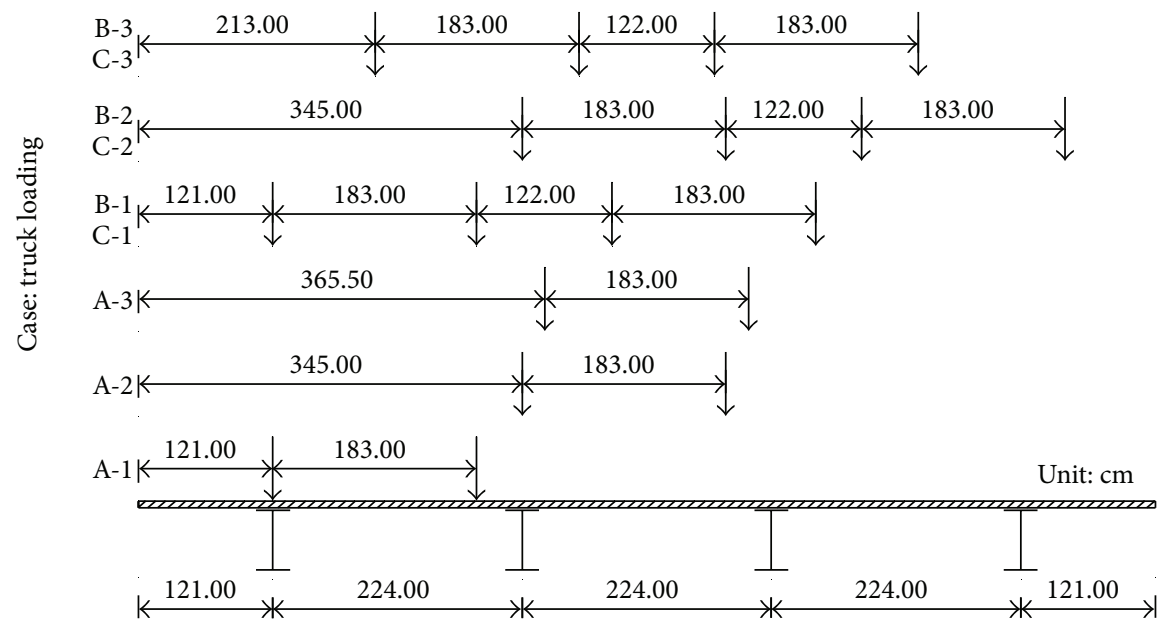

Dynamic model: 2 lanes, 4 stringers: G4

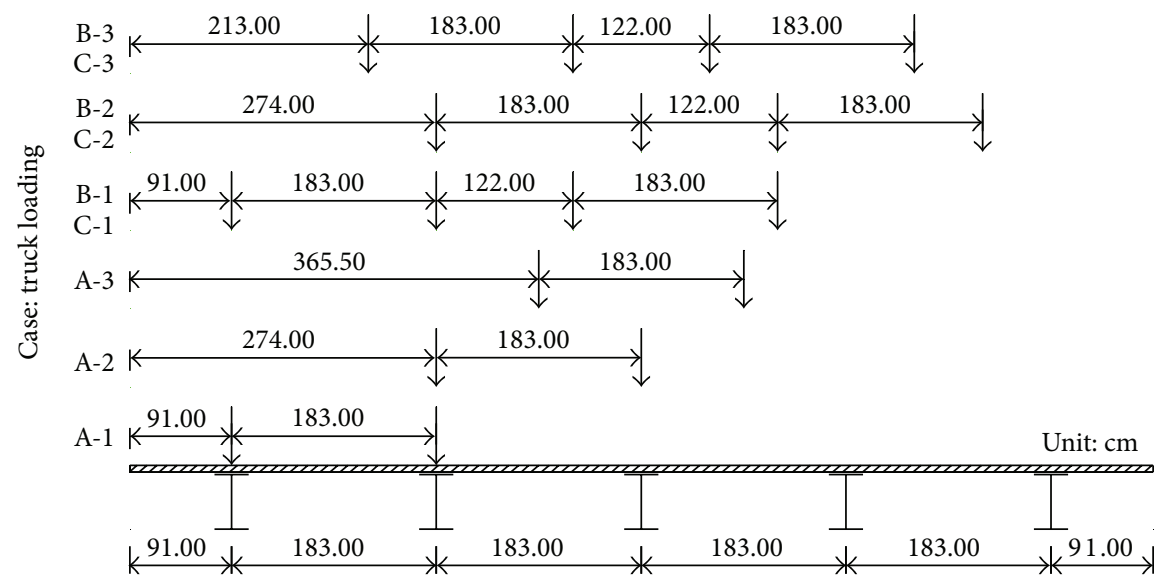

Dynamic model: 2 lanes, 5 stringers: G5

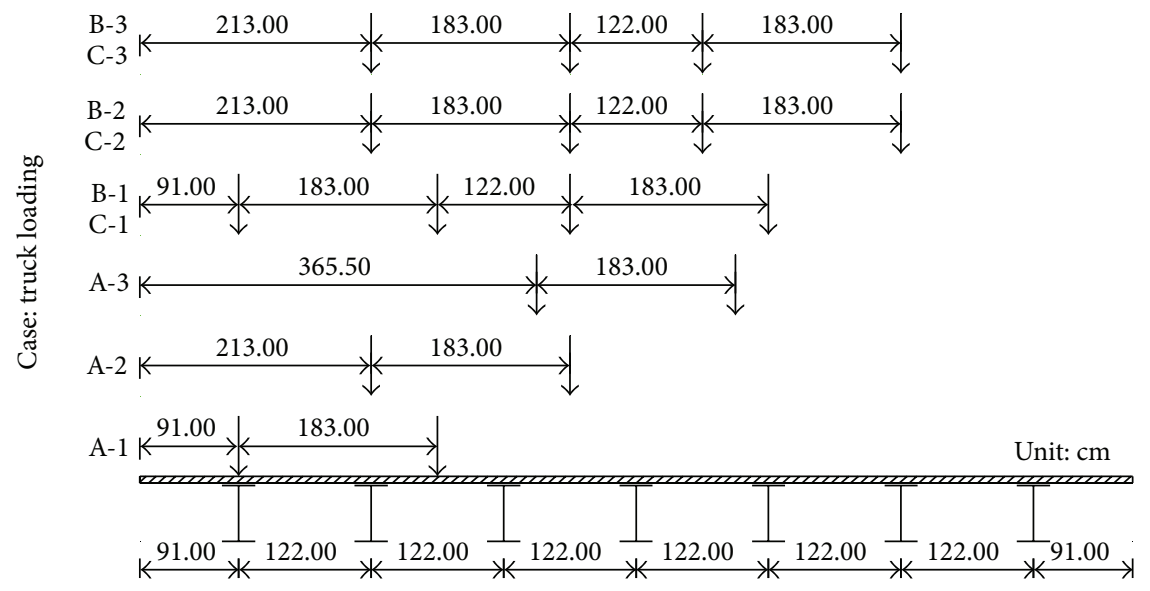

Dynamic model: 2 lanes, 7 stringers: G7

FIGURE 3: Summary of bridge models and design truck loading conditions. 
TABLE 3: Comparison between finite element and experimental results for FRP deck systems.

\begin{tabular}{|c|c|c|c|c|c|}
\hline \multirow{2}{*}{ Method } & \multirow{2}{*}{ Load case } & \multirow{2}{*}{ Applied load $(\mathrm{kN})$} & \multicolumn{2}{|c|}{ Average max. Deflection $(\mathrm{cm})$} & \multirow{2}{*}{ Relative deflection $(\mathrm{cm})$} \\
\hline & & & Stringer & FRP deck & \\
\hline Experimental & w w & \multirow{2}{*}{89.0} & 0.170 & 1.199 & 1.029 \\
\hline Finite element & 1 Case 1 I & & 0.067 & 1.078 & 1.011 \\
\hline Experimental & $\underline{w}$ & \multirow{2}{*}{89.0} & 0.106 & 0.146 & 0.040 \\
\hline Finite element & ${ }_{\text {Case } 2}^{I}$ & & 0.079 & 0.117 & 0.038 \\
\hline Experimental & $w w w$ & \multirow{2}{*}{177.9} & 0.170 & 0.516 & 0.346 \\
\hline Finite element & $I_{\text {Case } 3}^{I}$ & & 0.115 & 0.445 & 0.330 \\
\hline
\end{tabular}

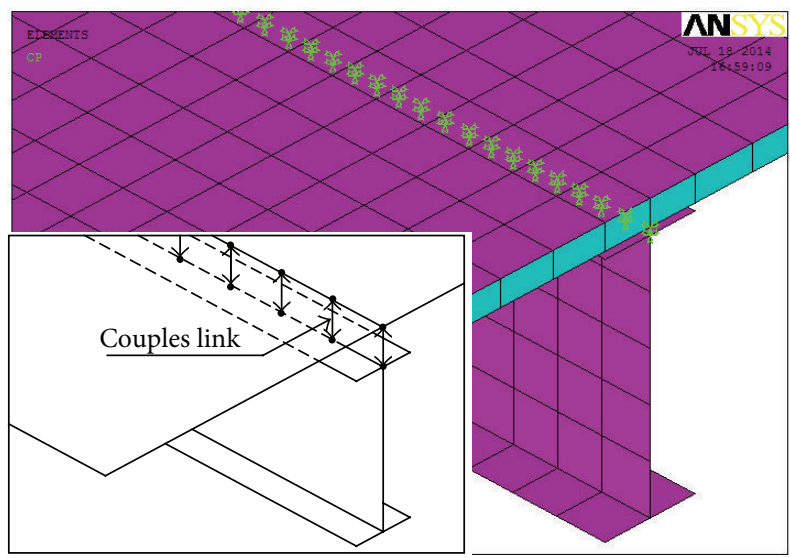

FIGURE 4: Link between deck and steel.

density function (PSD) was used for this purpose [24], since the bridge surface profiles are simply assumed to be random. In this study, the bridge surface roughness for good surface condition with roughness coefficient of $15\left(10^{-6}\right) \mathrm{m}^{3} /$ cycle was simulated using gap elements to interconnect with shell elements of FRP bridge models.

\section{Verification of Finite Element Models}

In this section, finite element bridge models were validated and calibrated through the experimental data $[25,26]$. Finite element bridge models were further verified by FRP deckstringer bridge system under AASHTO HS25 truck load and experimental modal analysis. The static load results and frequencies obtained from laboratory experiments were compared with the analytical results. For static load results, two different FRP deck-steel stringer systems were conducted under static wheel loads as follows: (1) FRP bridge deck was simply placed on two stringers with $3450 \mathrm{~mm}$ spacing and (2) FRP bridge deck was positioned on three stringers with equal spacing of $1730 \mathrm{~mm}$. Three different loading cases were performed to validate structural responses. Based on this study, the relative deflection of FRP deck systems was in agreement with the finite element results as shown in Table 3. The finite element results showed that the maximum differences in the relative deflection response comparing with the experimental results $[25,26]$ were less than 5 percent. It is obvious that the structural stiffness of FRP bridge deck system decreases with increases in stringer spacing, that is, fewer stringers. It was observed that the relative deflection of loading Case 1 was higher than the deflection limit $0.2 \%$ of stringer spacing (center to center). The warping and lateral torsional effects of steel stringers are attributed to high stresses and strains in the FRP deck flange, that is, global stiffness reduction of the FRP deck system.

For modal analysis, bridge deck finite element models were evaluated using block Lanczos method. The frequencies and mode shapes obtained from finite element results are summarized and compared with the experimental results $[25,26]$ as shown in Figure 7 . The finite element mode shapes and modal ordering were in agreement with the modes from the experimental data and the modal analysis. The percent difference between finite element and experimental results was ranged from 2 to 6 percent for FRP ProDeck8 bridge models and from 5 to 20 percent for FRP ProDeck4 bridge models. For ProDeck4 bridge models, a consistent difference may indicate an error in material properties such as inaccuracy in the data (e.g., material density) in the finite element model. It was observed that torsional mode was found to be the first mode shape in both the finite element and experimental results as the dominant mode. The lowest frequency of finite element first mode correlated with the lower torsional stiffness of FRP deck models. The material data using finite element models were obtained from the individual deck modules, and the plate action of FRP deck system was not accounted for in this finite element analysis. The plate action in FRP deck system under torsional 


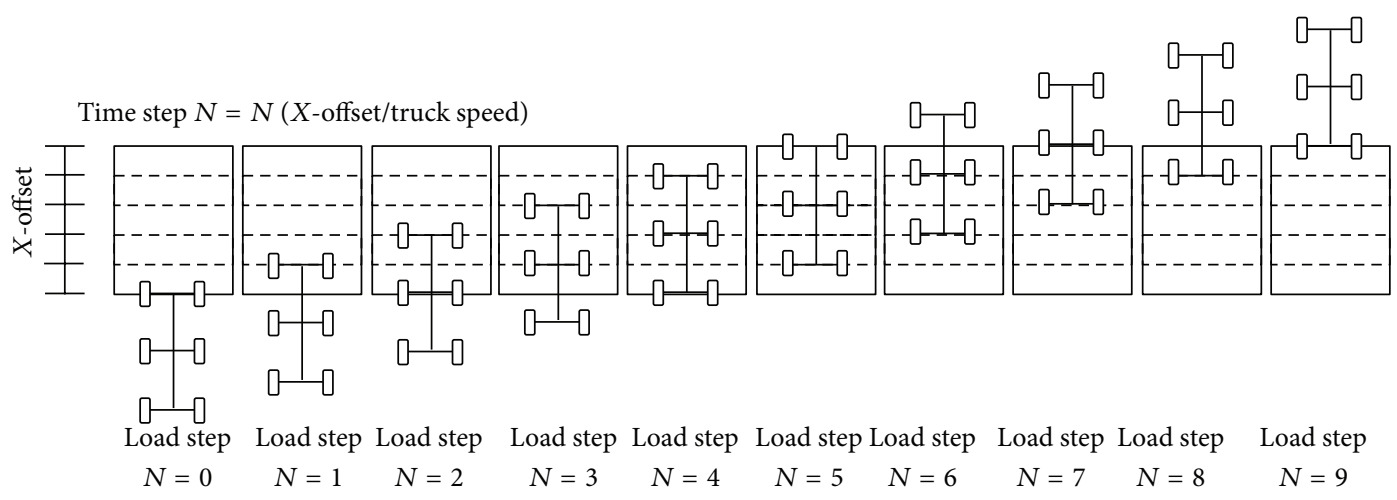

FIGURE 6: Simulation of moving truck using the load-step method.

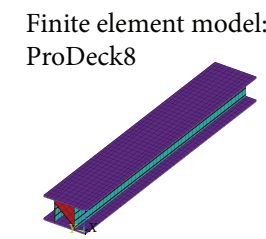

Mode 1: $78.9 \mathrm{~Hz}$

Mode 2: $202.9 \mathrm{~Hz}$

Mode 3: $351.3 \mathrm{~Hz}$

Experimental data: ProDeck8
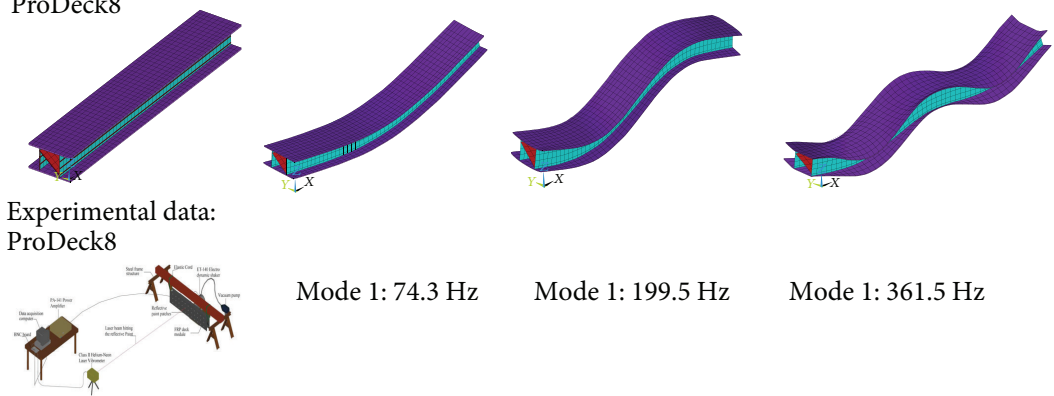

Mode 1: $74.3 \mathrm{~Hz}$

Mode 1: $199.5 \mathrm{~Hz}$

Mode 1: $361.5 \mathrm{~Hz}$

Finite element model:

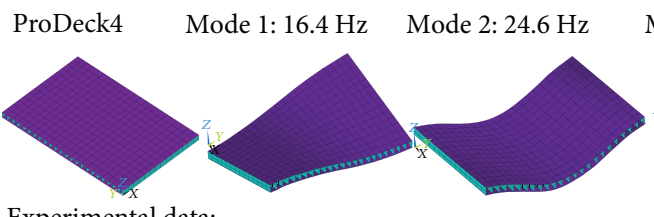

Experimental data: ProDeck4

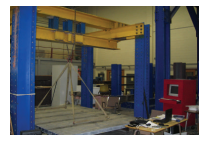

Mode 1: $21.4 \mathrm{~Hz} \quad$ Mode 2: $22.8 \mathrm{~Hz}$

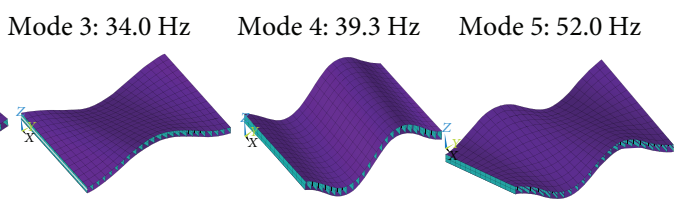

Mode 3: $38.9 \mathrm{~Hz}$

Mode 4: $41.5 \mathrm{~Hz}$
Mode 5: $57.1 \mathrm{~Hz}$

FIGURE 7: Frequencies and mode shapes of FRP composite decks.

and/or in-plane loadings is approximately about 20\% higher than an individual deck module without plate action (i.e., only beam effect). However, in case of an isotropic system (conventional materials), the plate action was about twice that of a beam. The lower plate action in FRP composite systems was attributed to lower Poisson's effect in the transverse direction compared to the longitudinal direction [19].

\section{Dynamic Load Allowance (DLA)}

Studying the dynamic effect of bridge models is tied to accurate determination of dynamic load allowance (DLA). Reviews of various design codes were reported for conventional highway bridges [22, 27, 28]. Disagreement on the dynamic load allowance results from different codes and studies were found due to various uncertainties in input parameters. Arguments on the dynamic load allowance evaluation have been inconclusive particularly in FRP bridge systems. The dynamic load allowance of FRP bridges was evaluated using the parametric study in this study. From the most rational approaches based on the theory of structural dynamics, the dynamic load allowance can be defined as the maximum instantaneous dynamic response divided by the maximum static response developed [2]. In this definition, both the maximum dynamic and static responses were found in the different locations through truck loading at different time intervals. The dynamic load allowance using deflection and strain calculation was commonly determined as given in the following equations, respectively:

$$
\begin{aligned}
& \text { DLA }=\frac{\left(D_{d \text { max }}-D_{s \max }\right)}{D_{s \max }}, \\
& \text { DLA }=\frac{\left(\varepsilon_{d \text { max }}-\varepsilon_{s \max }\right)}{\varepsilon_{s \max }},
\end{aligned}
$$



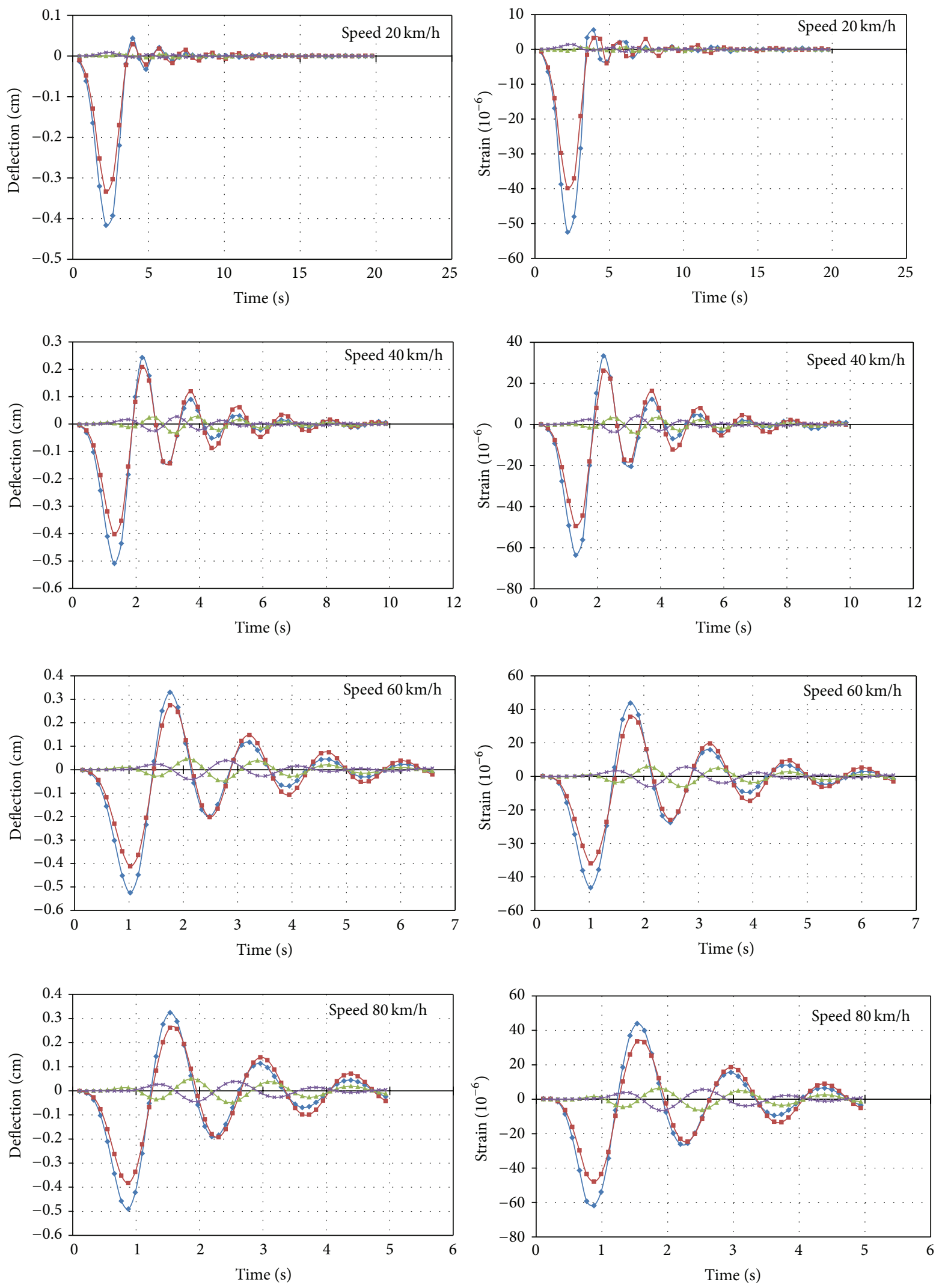

$\rightarrow$ Girder 1

$\longrightarrow$ Girder 3

$\longrightarrow$ Girder 1
$\longrightarrow$ Girder 2

$₫$ Girder 3

- Girder 2

$\star$ Girder 4

FIgURE 8: Continued. 

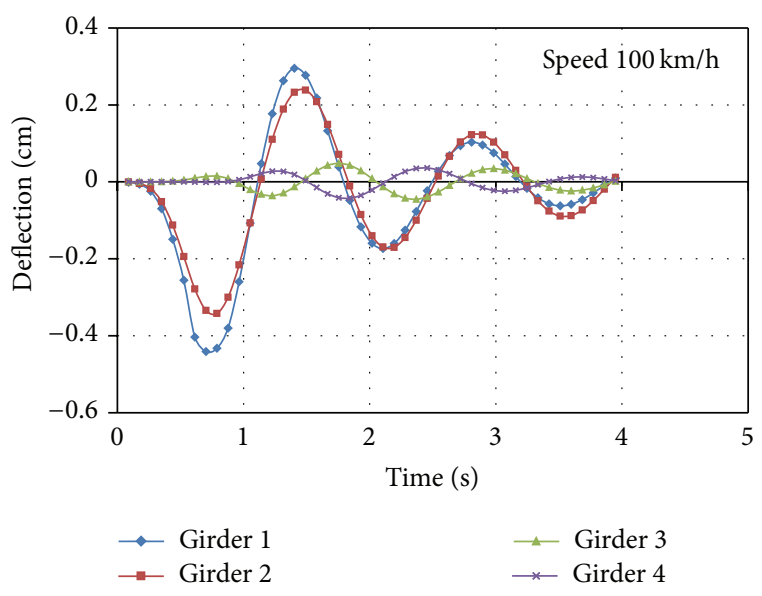

- Girder 3
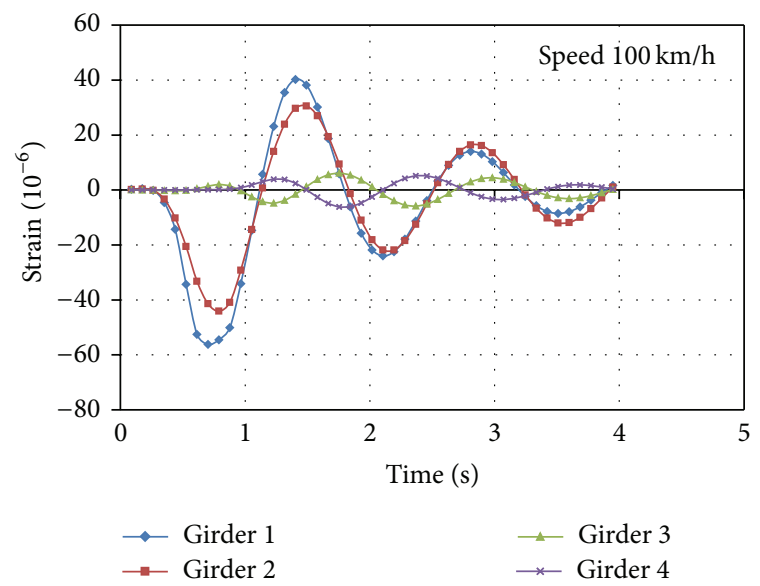

FIGURE 8: Time history of dynamic deflection and strain: FRP bridge (P4G4L12).

where $D_{d \max }$ is the maximum dynamic deflection, $D_{s \max }$ is the maximum static deflection, $\varepsilon_{d \max }$ is the maximum stain under the truck loading at traveling speed, $\varepsilon_{d \max }$ is the maximum dynamic strain under the truck loading at a specific traveling speed, and $\varepsilon_{s \max }$ is the maximum static strain under the truck loading.

\section{Parametric Study}

The parameters affecting the dynamic load allowance can be classified into two different main sources as (1) bridges including damping, frequency, and road surface profiles and (2) vehicles including speed, vehicle mass, damping, and tyre conditions. In general, the major parameters such as natural frequency, vehicle speed, bridge geometry and stiffness, and road surface dominate the dynamic responses of bridge models. In the following parametric study, a total of 648 FRP deck-steel stringer bridge models (composite and noncomposite cases) were investigated through finite element simulation. The dynamic load allowance in the present study was correlated with the previous research data [2$16,22,29$ ] obtained from fields, laboratory experiments, and analytical methods. Four parameters as (1) stringer spacing, (2) bridge span, (3) bridge deck, and (4) truck speed were mainly considered under cases of truck loading and a specific surface road condition as mentioned above. From analytical simulation, the time history of the dynamic deflection and strain at the midspan of the FRP bridge deck system model P4G4L12 (refer to Table 2: ProDeck4 bridge models with 4 steel stringers of $12 \mathrm{~m}$ span length) are presented as shown in Figure 8.

Accounting for three different cases of trucks and positions (Cases A, B, and C as in Figure 3) on the bridge models, investigations were conducted to understand variations in dynamic load allowance factor. The results showed that only one truck traveling over the bridge under a specific road surface condition affects the dynamic load allowance more than other load cases. The exterior stringer under the traffic lane experiences the greatest responses of both deflection and strain. Also, the dynamic load allowance provided by only one truck loading at the midtransverse bridge span is larger than that by the same truck at different positions. Since the maximum static response increases with the increase in the number of truck loadings, the maximum dynamic response slightly increases for the same number of truck loadings. The dynamic response results of FRP bridge models correspond to the previous study on concrete slab bridges [22] and Ontario Highway Bridge Design Code (OHBDC) [9]. The dynamic load allowance introduced by OHBDC [9] was provided as a function of the number of axles per span; that is, lower number of axles per span gives higher dynamic load allowance.

For the effect of vehicle speed, the vehicle speed ranging from $20 \mathrm{~km} / \mathrm{hr}$ to $100 \mathrm{~km} / \mathrm{hr}$ with an interval of $20 \mathrm{~km} / \mathrm{hr}$ was simulated using the time step method. To investigate the effect of different vehicle speed, dynamic responses at the same truck position (see the time history of the dynamic deflection in Figure 8) were considered for this purpose. It was clearly observed that the absolute dynamic deflection at the same truck loading position gradually increases with an increase in the truck loading speeds to $60 \mathrm{~km} / \mathrm{hr}$. When the truck speed is higher than $60 \mathrm{~km} / \mathrm{hr}$, the dynamic deflection decreases. Therefore, the higher truck speed may not increase the dynamic response of the FRP bridge models. The truck speed causing the maximum dynamic deflection at the same truck loading position can be defined as the critical speed or resonant speed. In our theoretical study, the critical speed or resonant effect of moving loads on bridges [29] is presented in terms of the fundamental frequency of the bridge, vehicle speed, and vehicle axle spacing. Originally, this critical speed was developed for railway bridges under a series of moving loads. As mentioned before [29], the critical speed is particularly applicable for short span bridges due to multiaxle vehicular loads considered as a series of moving loads. However, FRP bridges are significantly lighter than conventional bridges with low self-weight and damping, which may lead to excessive bridge dynamic response leading to loss of accuracy in critical speed determination. In addition, different trucks have different critical speeds resulting in bridge dynamic response as highest. The relations between the dynamic load allowance and truck speeds are illustrated in Figure 9. It was found that the truck speed of $40 \mathrm{~km} / \mathrm{hr}$ and $60 \mathrm{~km} / \mathrm{hr}$ results in the highest dynamic load allowance for different bridge spans. The finite element analytical results in 

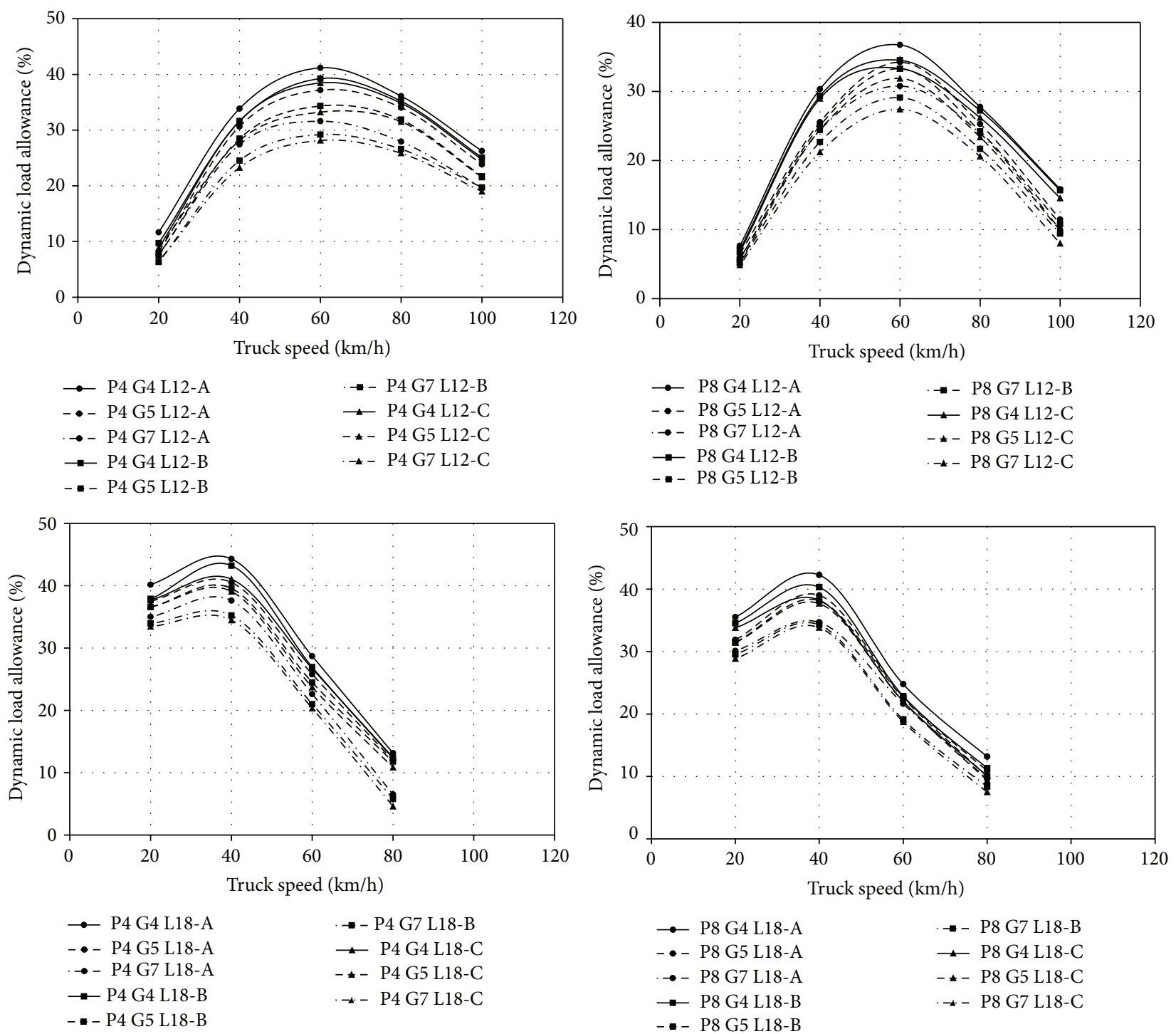

FIGURE 9: Relations between truck speeds and DLA.

this study were compared with the dynamic load allowance and speed provided by the Federal Highway Administration (FHWA 1995) [30]. It indicated that the trend of the dynamic load allowance is similar to that of FHWA (1995) [30]. It should be noted that the maximum dynamic load allowance occurs at lower vehicle speeds when the length of FRP bridge span increases due to an increase of bridge fundamental frequency. From various specifications [5-16], it is seen that the dynamic load allowance based on a bridge span length underestimates the values for the FRP bridges by about $25 \%$ as shown in Table 4. The dynamic load allowance and stinger spacing relations are shown in Figure 10. The dynamic load allowance tended to decrease as the span length of the bridge increases while the dynamic load allowance decreased with increase in span length.

\section{Simplified Dynamic Load Allowance}

From our results, better prediction of the dynamic load allowance for FRP bridges may be accomplished by considering several parameters as natural frequency, span length, and vehicle speed. The dynamic load allowance can be presented in terms of an allowance $(\beta)$ for initial vibrations of vehicle coming onto the bridge and the effects $(\alpha)$ from a smoothly rolling mass crossing a stringer as given in (3). Equation (3) is based on the previous study proposed by Walker and Veletsos [31]. The dynamic load allowance can be directly determined by adding effects of initial oscillations $(\beta)$ and a smoothly rolling mass crossing a beam $(\alpha)$ together. By using DLA data (finite element results) with bridge and vehicle parameters, the allowance factor $(\beta)$ can be estimated for simplified dynamic load allowance equation. Thus, the upper and lower bounds dynamic load allowance can be developed using this simplified equation with varying bridge frequency:

$$
\begin{aligned}
& \text { DLA }=\beta+\alpha \text { or } \\
& \text { DLA }=\beta+\frac{V}{(2 L f)},
\end{aligned}
$$


TABle 4: Dynamic load allowance of various specifications.

\begin{tabular}{|c|c|c|c|}
\hline \multirow{2}{*}{ Specification } & \multirow{2}{*}{ Dynamic load allowance } & \multicolumn{2}{|c|}{ Span length } \\
\hline & & $12 \mathrm{~m}$ & $18 \mathrm{~m}$ \\
\hline AASHTO 1998 [5] & 0.33 & 0.33 & 0.33 \\
\hline AASHTO 2007 [6] & $50 /(125+L), L$ in $\mathrm{ft}$ & 0.30 & 0.27 \\
\hline BS5400 [7] & 0.25 & 0.25 & 0.25 \\
\hline JRAS [8] & $20 /(50+L), L$ in $\mathrm{m}$ & 0.32 & 0.29 \\
\hline OHBDC [9] & 0.4 for one axle & 0.40 & 0.40 \\
\hline France (modified 1989) [10] & $0.8 /(1+0.2 L), L$ in $\mathrm{m}$ & 0.24 & 0.17 \\
\hline DIN 1072-1987 [11] & $0.4-0.008 L, L$ in $\mathrm{m}$ & 0.30 & 0.26 \\
\hline Norm NEM 1008 [13] & $40 /(100+L), L$ in $\mathrm{m}$ & 0.36 & 0.34 \\
\hline Australia NAASRA 1989 [14] & $50 /(125+L) \leq 0.3, L$ in $\mathrm{ft}$ & 0.30 & 0.27 \\
\hline Switzerland SIA160 [15] & $0.05(L+100) /(L+10), L$ in $\mathrm{m}$ & 0.25 & 0.21 \\
\hline Korea KBDS [16] & $15 /(40+L) \leq 0.3, L$ in $\mathrm{m}$ & 0.29 & 0.26 \\
\hline Parametric study (note: results from ProDeck4 and ProDeck8 models) & \multicolumn{3}{|c|}{0.4 (average for $12-18 \mathrm{~m}$ ) } \\
\hline
\end{tabular}
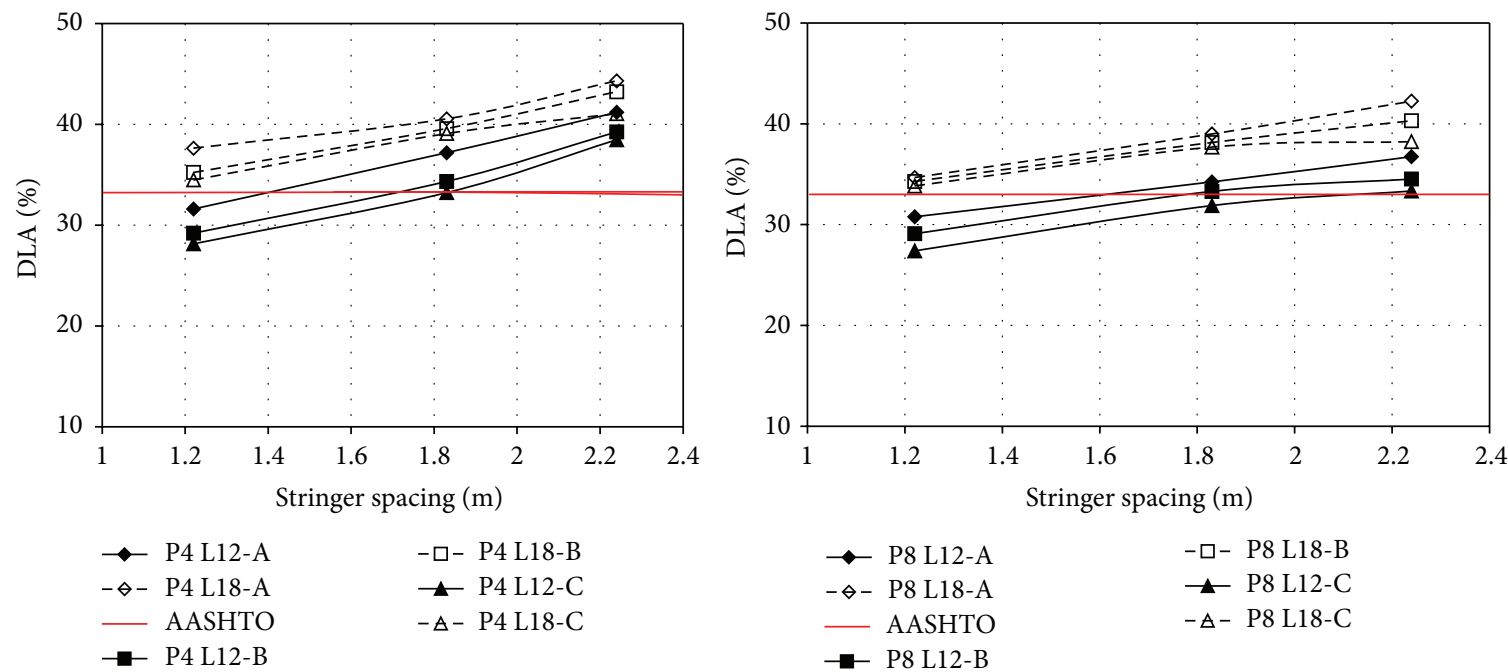

FIGURE 10: Relations between stringer spacing and DLA.

where $V$ is a truck speed $(\mathrm{m} / \mathrm{s}), L$ is a span length $(\mathrm{m})$, and $f$ is the first flexural frequency $(\mathrm{Hz})$.

Based on this parametric study (the first flexural frequency of the finite element models is equal to $3.5 \mathrm{~Hz}$ ), the allowance $(\beta)$ for initial vibrations of a vehicle onto the FRP bridges was evaluated and suggested to be 0.30 . Alternatively, the dynamic load allowance of the FRP bridges may be determined using $0.3+V /(2 L f)$ for the bridge length of $10-20 \mathrm{~m}$. For example, the relation between dynamic load allowance and bridge span based on (3) is presented and compared with the standard codes of practice as shown in Figure 11.

Lack of accurate data leads to having a more conservative dynamic load allowance value for design purposes. The simplified dynamic load allowance using the first major frequency of FRP bridge models was developed herein. The results from various parameters in (3) are used to arrive at both the upper and lower limits of the dynamic load allowance as shown in Figure 12. These upper and lower

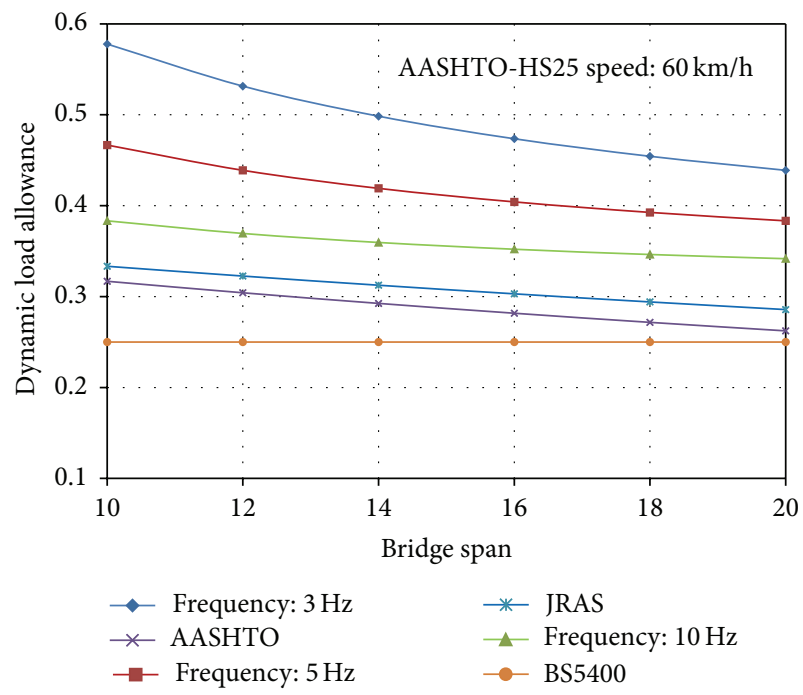

Figure 11: DLA with different bridge frequency and span length. 


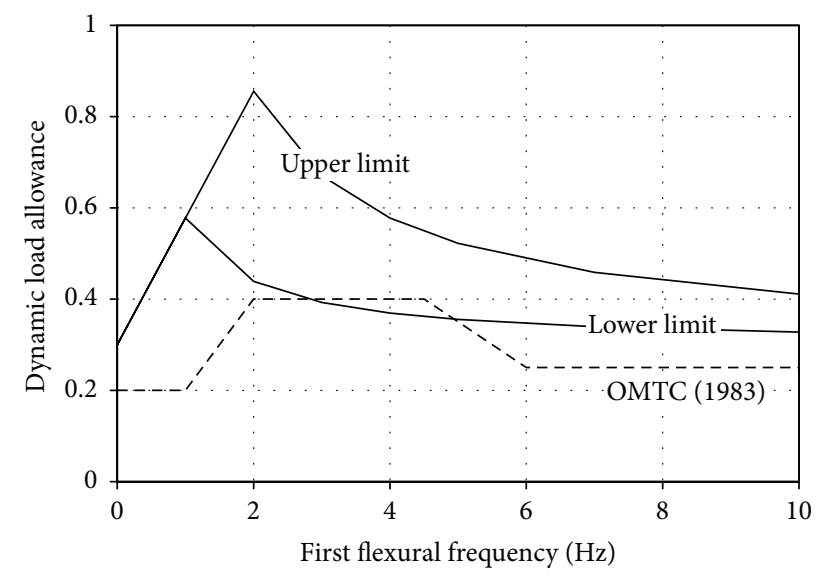

FIgURE 12: Relation between DLA and frequency.

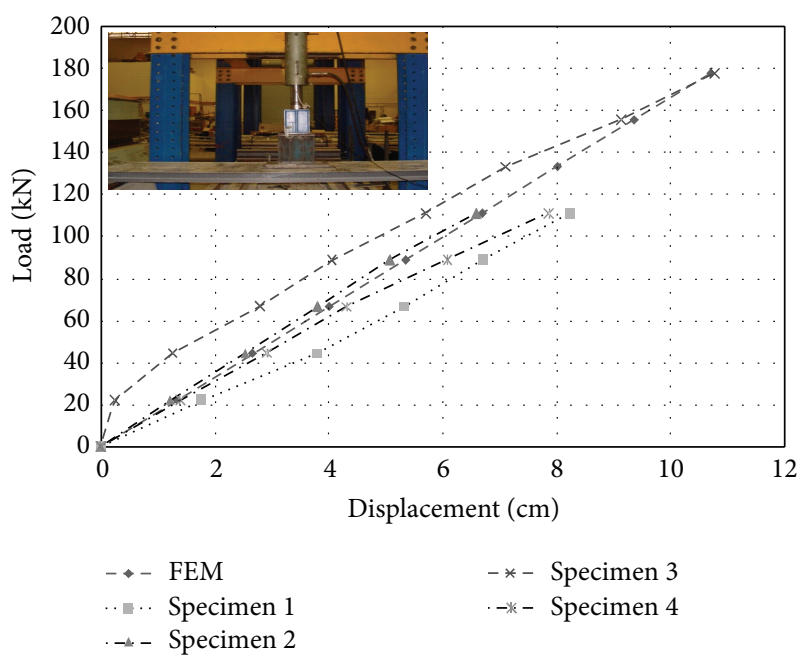

FIGURE 13: Load-deflection response of a single ProDeck4 module.

bounds were established as preliminary design guidelines. It should be noted that the upper and lower bounds of the dynamic load allowance are based on the dynamic response of FRP bridge models as mentioned in this study.

\section{Conclusions}

The present study has aimed at investigating dynamic responses of FRP bridge systems. A total of 648 FRP bridge models in different bridge configurations and load patterns were simulated using finite element analysis. The dynamic responses of FRP bridge models with noncomposite structural action between FRP deck and a stringer are higher than those with $100 \%$ structural composite action. The trend of the dynamic load allowance with various vehicle speeds is similar to that given by FHWA (1995). From standard specifications [5-16], the dynamic load allowances may not be an accurate representation of the field and analytical data for FRP bridge systems. The dynamic load allowance based on current design specifications underestimates the values for FRP bridges by about $25 \%$. A more accurate prediction of the dynamic load allowance for FRP bridges is proposed herein by accounting for realistic input parameters such as a natural frequency, span length, and vehicle speed. The dynamic load allowance equation in terms of an allowance $(\beta)$ for initial vibrations of vehicle and the factor $(\alpha)$ about a smoothly rolling mass was developed. The simplified dynamic load allowance using the first major frequency was established. Both the upper and lower bounds of the dynamic load allowance are suggested as a design guidance for FRP bridges with span length ranging from 10 to $20 \mathrm{~m}$.

\section{Appendix}

Component level: load and deflection response of a single ProDeck4 module is presented (see Figure 13).

\section{Conflict of Interests}

The authors declare that there is no conflict of interests regarding the publication of this paper.

\section{Acknowledgments}

This study was partially supported by Structural Engineering and Applied Mechanics (STREAM) Research Group under Grant ENG-51-2-7-11-022-S, Department of Civil Engineering, Faculty of Engineering, Prince of Songkla University, Hat Yai, Songkhla, Thailand. The authors would also like to thank anonymous reviewers for their valuable and constructive comments.

\section{References}

[1] I. M. Daniel and O. Ishai, Engineering Mechanics of Composite Materials, Oxford University Press, Oxford, UK, 2nd edition, 2006.

[2] S. Aluri, C. Jinka, and H. V. S. GangaRao, "Dynamic response of three fiber reinforced polymer composite bridges," Journal of Bridge Engineering, vol. 10, no. 6, pp. 722-730, 2005.

[3] Y. Zhang and C. S. Cai, "Load distribution and dynamic response of multi-girder bridges with FRP decks," Engineering Structures, vol. 29, no. 8, pp. 1676-1689, 2007.

[4] M. J. Robinson and J. B. Kosmatka, "Dynamic response of a light-weight composite bridge," in Proceedings of the 8th International Conference on Structural Dynamics (EURODYN '11), pp. 1430-1437, Leuven, Belgium, July 2011.

[5] American Association of State Highway and Transportation Officials (AASHTO), Standard Specifications for Highway Bridges, American Association of State Highway and Transportation Officials (AASHTO), Washington, DC, USA, 1998.

[6] American Association of State Highway and Transportation Officials (AASHTO), LRFD Bridge Design Specification, SI Unit, American Association of State Highway and Transportation Officials (AASHTO), Washington, DC, USA, 3rd edition, 2007.

[7] BS5400, Concrete and Composite Bridge Part 2: Specification for Loads, BriBritish Standards Institution, London, UK, 1978.

[8] Japan Road Association's Specification (JRAS), Part 1: Common Specifications for Highway Bridges, Japan Road Association (JRA), Tokyo, Japan, 1996.

[9] OHBDC, Ontario Highway Bridges Design Code, Highway Engineering Division, Ministry of Transportation and Communications, Ontario, Canada, 1983. 
[10] Ontario Ministry of Transportation (OMT), Ontario Highway Bridges Design Code, Highway Engineering Division, Ontario, Canada, 3rd edition, 1991.

[11] Cahier des Prescriptions Communes Applicable aux Marches de Travaux Publis Relevant des Services de l'Equipement, Ministere de l'Equipement et du Logement, Ministere des Transports, Paris, France, 1973.

[12] Deutsche Industire Normen (DIN 1072), Road and Footbridges: Design Loads, Deutsche Industire Normen (DIN), Berlin, Germany, 1983.

[13] NEN 1008: Voorschriften voor het Ontwerpen van Stalen Bruggen (VOSB 1963), NNI, 1963.

[14] NAASRA, Bridge Waterways Hydrology and Design, National Association of Australia State Road Authorities, Sydney, Australia, 1989.

[15] SIA160: Einwirkungen auf Tragwerke, Entwurf, Schweizerischer Ingenieur- und Architektenverein, Zürich, Switzerland, 1988.

[16] Korea Bridge Design Specifications (KBDS), Roadway Standard Specification Codes, Korea Roadway Transportation Association (KRTA), Ministry of Land, Transport and Maritime Affairs, 2005.

[17] W. Prachasaree, P. Sookmanee, S. Limkatanyu, and H. V. S. GangaRao, "Simplified load distribution factors for fiber reinforced polymer composite bridge decks," Baltic Journal of Road and Bridge Engineering, vol. 8, no. 4, pp. 271-280, 2013.

[18] W. Prachasaree, H. V. S. Gangarao, and V. Shekar, "Performance evaluation of FRP bridge deck under shear loads," Journal of Composite Materials, vol. 43, no. 4, pp. 377-395, 2009.

[19] W. Prachasaree, H. V. S. Gangarao, and V. Shekar, "Performance evaluation of FRP bridge deck component under torsion," Journal of Bridge Engineering, vol. 11, no. 4, Article ID 006604QBE, pp. 430-442, 2006.

[20] ANSYS, ANSYS Release 9.0 Documentation, Version 9.0, Swanson Analysis Systems, 2004.

[21] B. Wan, D. C. Rizos, M. F. Petrou, and K. A. Harries, "Computer simulations and parametric studies of GFRP bridge deck systems," Composite Structures, vol. 69, no. 1, pp. 103-115, 2005.

[22] National Cooperative Highway Resaerch Program (NCHRP), Dynamic Impact Factors for Bridges, Synthesis 266, National Acedemy Press, Washington, DC, USA, 1998.

[23] M. Chiewanichakorn, A. J. Aref, and S. Alampalli, "Dynamic and fatigue response of a truss bridge with fiber reinforced polymer deck," International Journal of Fatigue, vol. 29, no. 8, pp. 1475-1489, 2007.

[24] C. J. Dodds and J. D. Robson, "The description of road surface roughness," Journal of Sound and Vibration, vol. 31, no. 2, pp. 175-183, 1973.

[25] C. S. Jinka, Dynamic response evaluation of fiber reinforced composite bridge decks and bridges [M.S. thesis], Department of Civil Engineering, West Virginia University, Morgantown, WVa, USA, 2003.

[26] S. Aluri, Updating low-profile FRP deck FE model using experimental modal analysis [M.S. thesis], Department of Mechanical Engineering, West Virginia University, Morgantown, WVa, USA, 2006.

[27] B. Bakht and S. G. Pinjarkar, "Review of dynamic testing of highway bridges," Transportation Research Record, vol. 1223, pp. 93-100, 1989.

[28] L. Deng, Y. Yu, Q. Zou, and C. S. Cai, "State-of-the-art review of dynamic impact factors of highway bridges ," Journal of Bridge Engineering, vol. 20, no. 5, Article ID 04014080, 2015.
[29] J. Li and M. Su, "The resonant vibration for asimply supported girder bridge under high-speed trains," Journal of Sound and Vibration, vol. 224, no. 5, pp. 897-915, 1999.

[30] Federal Highway Administration (FHWA), Load and Resistance Factor Design for Highway Bridges, FHWA, Washington, DC, USA, 1995.

[31] W. H. Walker and A. S. Veletsos, "Response of simple-span highway bridges to moving vehicles," Bulletin Experiment Station 124, College of Engineering, University of Illinois, Champaign, Ill, USA, 1966. 

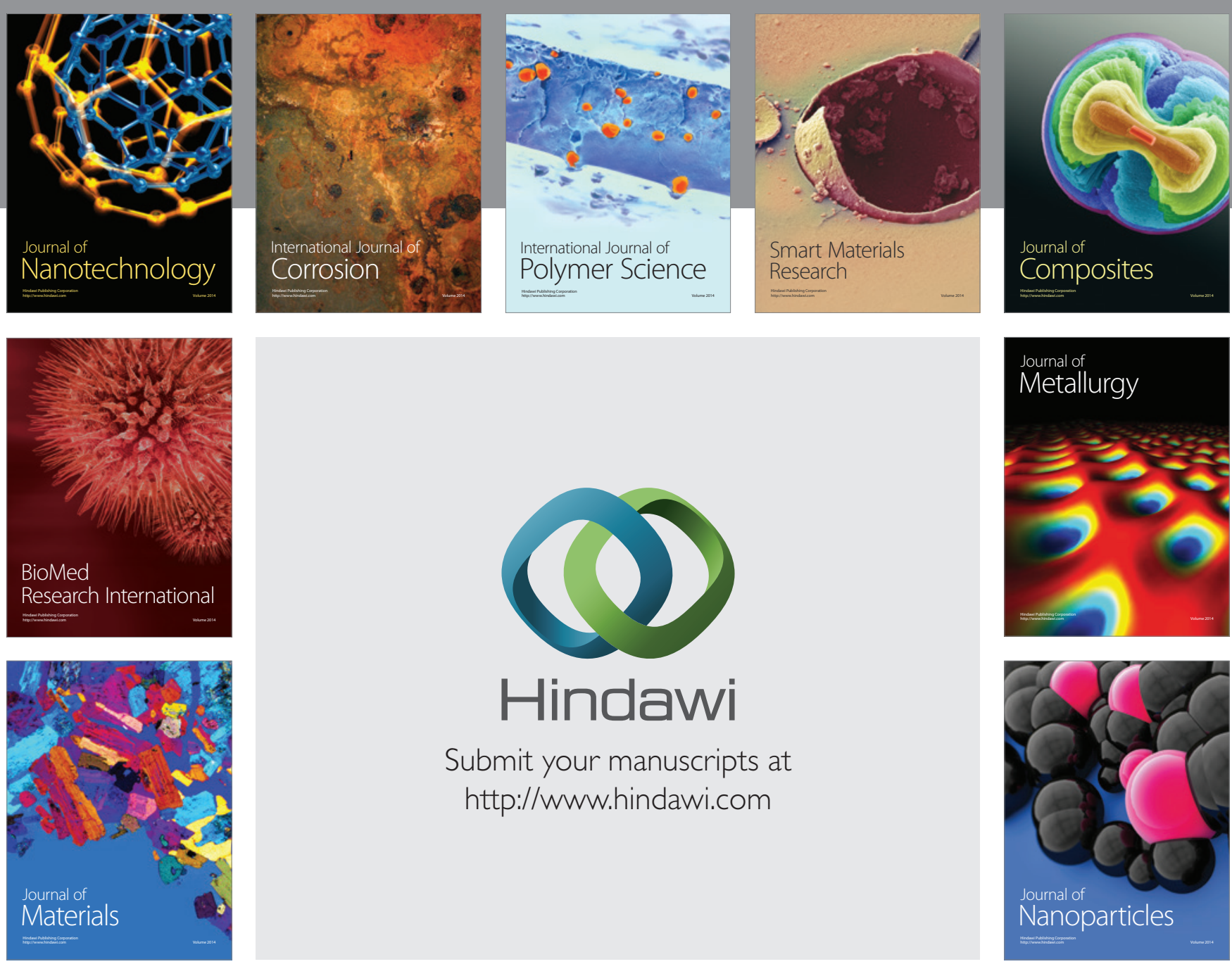

Submit your manuscripts at http://www.hindawi.com
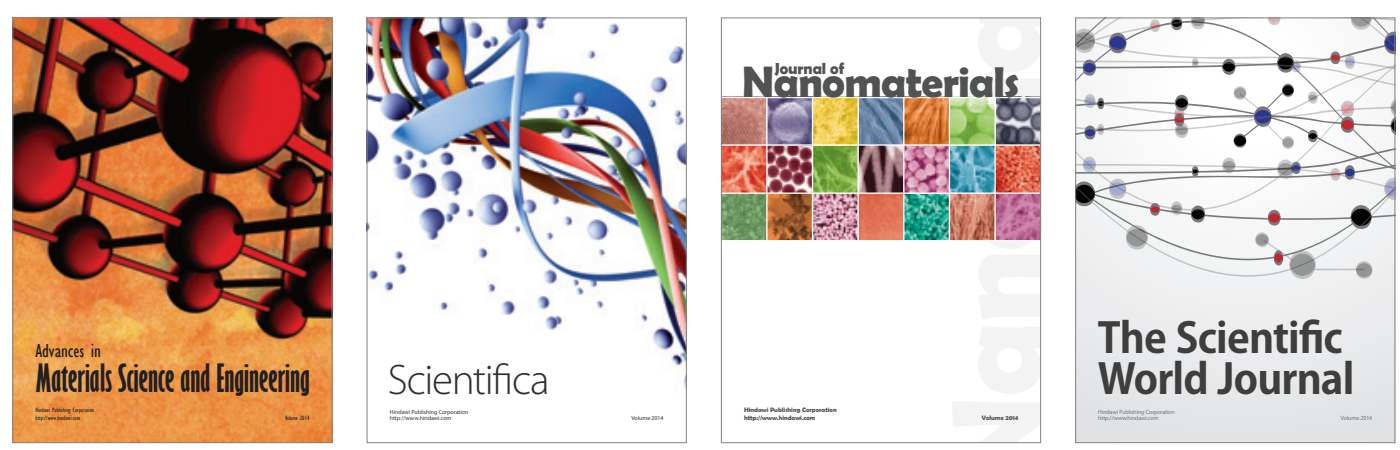

\section{The Scientific World Journal}
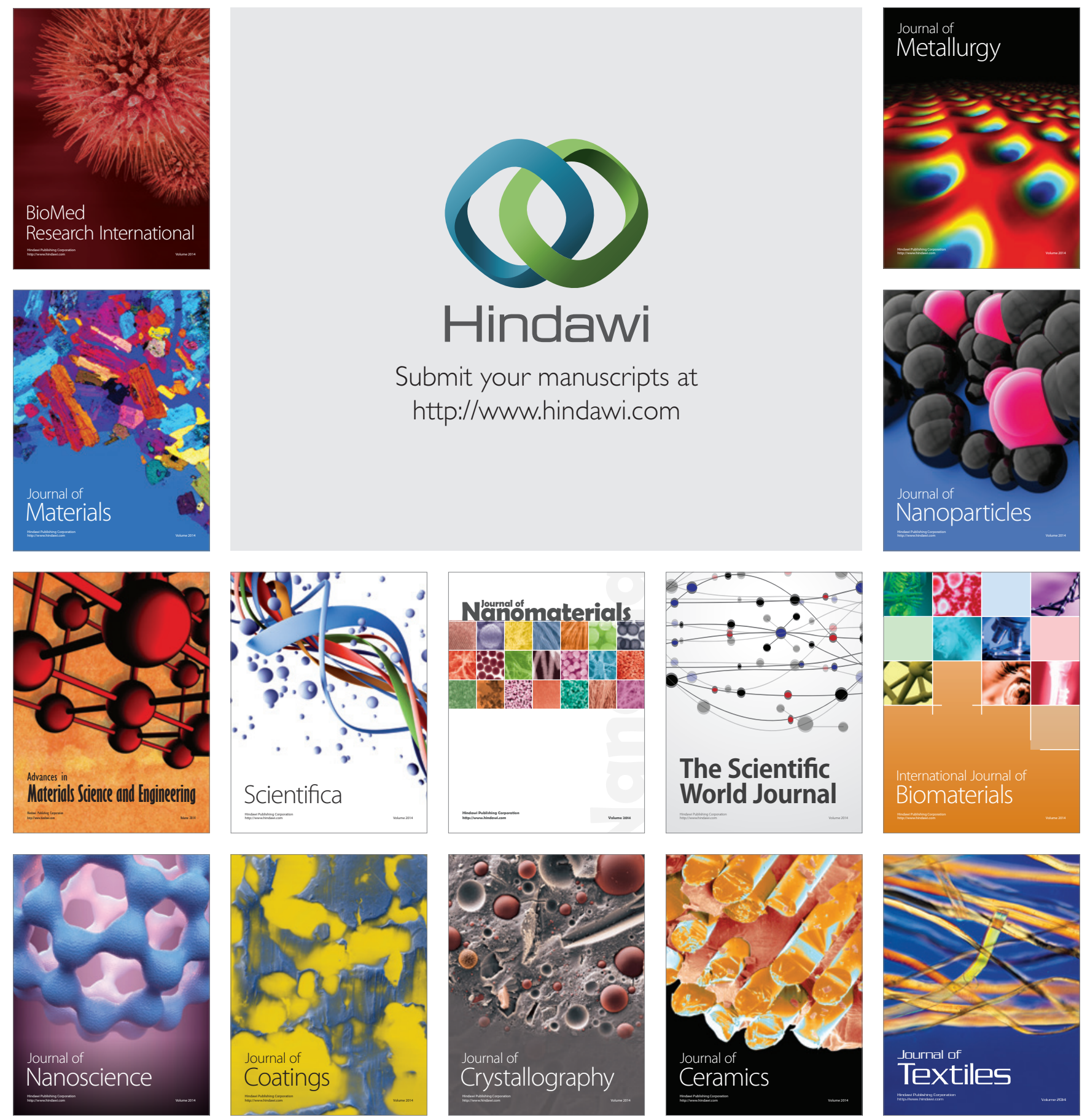